\title{
The Phenomenal Basis of Epistemic Justification
}

\author{
Declan Smithies
}

For much of the last century, phenomenal consciousness occupied a curious status within philosophy of mind: it was central in some ways and yet peripheral in others. On the one hand, this topic attracted a significant amount of philosophical interest owing to metaphysical puzzlement about the nature of phenomenal consciousness and its place in the physical world. On the other hand, this metaphysical puzzlement also provided much of the impetus for a research program of understanding the mind as far as possible without making reference to phenomenal consciousness.

One defining characteristic of this research program was the idea that the "hard problem" of explaining phenomenal consciousness could be divorced from the comparatively "easy problems" of explaining mental representation and our knowledge of the external world. ${ }^{1}$ For instance, one of the central projects in late twentieth century philosophy of mind was to explain mental representation in terms of causal connections between the mind and the external world specified without appealing to phenomenal consciousness. ${ }^{2}$ At the same time, one of the central projects in epistemology was to explain knowledge and justified belief in terms of causal connections between the mind and the external world; again, specified without reference to phenomenal consciousness. ${ }^{3}$

One of the new waves in philosophy of mind over the last couple of decades has been a growing recognition of the importance of phenomenal consciousness and its centrality in our understanding of the mind. In philosophy of mind, it has become 
increasingly common to argue that phenomenal consciousness is the basis of mental representation and hence that the problem of explaining mental representation cannot be divorced from the problem of explaining phenomenal consciousness. ${ }^{4}$ This chapter argues for a related thesis in epistemology - namely, that phenomenal consciousness is the basis of epistemic justification and hence that the problem of explaining epistemic justification cannot be divorced from the problem of explaining phenomenal consciousness. ${ }^{5}$

These two claims about the role of phenomenal consciousness are related in ways that are symptomatic of the more general interactions between issues in epistemology and philosophy of mind. If phenomenal consciousness is the basis of epistemic justification, as I will be arguing, then we can ask what it must be like in order to play this epistemic role. Arguably, phenomenal consciousness cannot play this epistemic role if it is constituted by brute, non-representational sensations or "qualia". On the contrary, the role of phenomenal consciousness in grounding epistemic justification depends upon its role in grounding mental representation. More specifically, we do not need the strong thesis that all mental representation has its source in phenomenal consciousness, but only the weaker thesis that some mental representation has its source in phenomenal consciousness - namely, the kind of mental representation that plays an epistemic role. ${ }^{6}$

This chapter is primarily concerned with arguing for the epistemic role of phenomenal consciousness, rather than its role in grounding mental representation, although these issues are interconnected in ways that will emerge in the discussion to follow. In the first three sections, I motivate the connection between phenomenal 
consciousness and epistemic justification by appealing to intuitive judgments about thought-experiments and I defend it against objections. In the final section, I sketch a more theoretical line of argument that the connection between phenomenal consciousness and epistemic justification best explains the independently motivated thesis of access internalism. The result is a theory of epistemic justification that is designed to bring intuition and theory into reflective equilibrium.

\section{I}

What is the basis of epistemic justification? A presupposition of the question is that facts about epistemic justification are not without some basis: they are not brute facts. More generally, all epistemic facts are determined by non-epistemic facts in the sense that there can be no epistemic differences between situations without some corresponding non-epistemic differences in virtue of which those epistemic differences obtain. Determination, unlike supervenience, is an asymmetric relation that captures an order of explanatory priority: epistemic facts supervene on their non-epistemic determinants, and vice versa, but epistemic facts are determined by their non-epistemic determinants, and not vice versa. In a slogan, the determinants of epistemic facts are epistemic difference-makers.

This chapter is concerned to address the following question about the determinants of epistemic justification:

The Question: What are the non-epistemic facts that determine the epistemic facts about which doxastic attitudes one has justification to hold? 
To clarify, the target question is exclusively concerned with epistemic justification, rather than practical justification - that is, the kind of justification that attaches to beliefs and other doxastic attitudes as opposed to actions. Moreover, it is concerned with epistemic justification as distinct from any other epistemic properties that may be necessary for knowledge, such as reliability, safety, sensitivity, and so on. And finally, it is concerned with epistemic justification in the propositional sense, rather than the doxastic sense - that is, the sense in which one has justification to hold certain doxastic attitudes regardless of the way in which one holds them or, indeed, whether one holds them at all. ${ }^{7}$

Reliabilism is one of the mainstream accounts of the determinants of epistemic justification. According to reliabilism, epistemic facts about which doxastic attitudes one has justification to hold are determined by non-epistemic facts about the reliability or unreliability of one's doxastic dispositions:

Reliabilism: The reliability of one's doxastic dispositions determines which doxastic attitudes one has justification to hold.

On a simple version of reliabilism, one has justification to hold a belief if and only if one has a disposition to hold the belief that is sufficiently reliable in the sense that it generates a sufficiently high ratio of true beliefs to false beliefs in sufficiently similar counterfactual circumstances. ${ }^{8}$ 
Reliabilism is subject to well-known counterexamples which illustrate that differences in the reliability of one's doxastic dispositions are neither necessary nor sufficient to make a difference with respect to epistemic justification:

Envatment: My envatted mental duplicate has justification to form beliefs on the basis of perceptual experience, memory, testimony, and so on, although forming beliefs in this way is unreliable in the circumstances. ${ }^{9}$

Clairvoyance: My clairvoyant mental duplicate lacks justification to believe on the basis of blind hunches, wishful thinking, and so on, although forming beliefs in this way is reliable in the circumstances. ${ }^{10}$

These cases have a common structure: in each case, we vary the facts about the reliability of the subject's doxastic dispositions, but we do not thereby vary the ways in which the subject has justification to form beliefs, so long as we hold fixed the facts about the subject's mental states. Moreover, the common structure between these cases suggests a common explanation: namely, that epistemic justification is not determined by facts about the reliability of the connections between the subject's mental states and the external world, but rather by facts about the subject's mental states themselves.

Mentalism is a prominent alternative to reliabilism, which holds that epistemic facts about which doxastic attitudes one has justification to hold are determined by non-epistemic facts about one's mental states: 
Mentalism: One's mental states determine which doxastic attitudes one has justification to hold. ${ }^{11}$

Mentalism implies that mental duplicates are also duplicates with respect to which doxastic attitudes they have justification to hold. For instance, if I have justification to form beliefs on the basis of perceptual experience, memory, testimony, and so on, then so does any mental duplicate of mine, even if forming beliefs in that way is unreliable in the circumstances. Similarly, if I lack justification to form beliefs on the basis of blind hunches, wishful thinking, and so on, then so does any mental duplicate of mine, even if forming beliefs in that way is reliable in the circumstances. In this way, mentalism provides a common explanation of intuitive verdicts about envatment and clairvoyance alike.

The problem with mentalism as formulated here is that not all mental states are justificational difference-makers. For instance, my envatted duplicate does not share all my factive mental states, such as seeing that there is a cup on the table, so we need a restriction to non-factive mental states in order to explain why he has justification to adopt all the same doxastic attitudes. ${ }^{12}$ Indeed, we need to impose further restrictions, since not all one's non-factive mental states are justificational difference-makers. Consider the subdoxastic mental representations that figure in computational explanations in cognitive science, such as Chomsky's (1965) tacit knowledge of syntax and Marr's (1982) primal, 2.5D and 3D sketch: these 
subdoxastic mental representations do not play any epistemic role in determining which doxastic attitudes one has epistemic justification to hold. ${ }^{13}$

Therefore, proponents of mentalism need to address the following question:

The Generalization Question: Which mental states play an epistemic role in determining which doxastic attitudes one has justification to hold?

It is tempting to answer this question by invoking Dennett's (1969) distinction between personal and subpersonal levels. Subdoxastic mental representations are not states of the person, but rather states of parts of the person - namely, their computational subsystems. And so one might propose that epistemic justification is determined solely by personal-level mental states. But this is no more than a promissory note in the absence of a further account of which mental states are properly attributed to the person as opposed to the person's subsystems. The same problem affects the proposal that epistemic justification is determined solely by mental states that figure within the subject's perspective or point of view on the world. Once again, the question remains which mental states figure within the subject's perspective in the sense that is relevant for epistemic justification.

Broadly speaking, there are two options for explicating the sense in which epistemic justification depends upon the subject's perspective: one can appeal either to phenomenal consciousness or to functional role. In the next section, I decide between these options by exploiting a series of imaginary variations on the empirical phenomenon of blindsight. I argue that there is an epistemic asymmetry 
between conscious sight and blindsight, which is best explained by appealing to phenomenal differences, rather than functional differences, between them. The general strategy is to argue that however much we complicate the functional role of blindsight, the epistemic asymmetry with conscious sight remains so long as there is a corresponding phenomenal asymmetry. Therefore, I conclude that phenomenal consciousness plays a crucial role in the determination of epistemic justification.

\section{II}

My starting point is that conscious perceptual experience plays a foundational epistemic role in providing a source of justification for beliefs about the external world. This is not to prejudge questions about the structure of the justification that perceptual experience provides. On one view, perceptual experience provides immediate, non-inferential justification for beliefs about the external world. On another view, perceptual experience provides justification for beliefs about the external world in a way that is inferentially mediated by justification for beliefs about the reliability of perceptual experience. But even on the second view, perceptual experience plays a foundational role in providing immediate, noninferential justification for beliefs about which perceptual experiences one is having at any given time. So, on either view, one's justification for beliefs about the external world has its source in their relations to perceptual experience and not solely in their relations to other beliefs. ${ }^{14}$

Moreover, it is extremely plausible that perceptual experience plays this foundational epistemic role in virtue of its phenomenal character. It is because 
perceptual experience has the phenomenal character of confronting one with objects and properties in the world around me that it justifies forming beliefs about those objects and properties. This point is best illustrated by reflecting on cases in which the phenomenal character of perceptual experience is missing.

For example, subjects with blindsight lose conscious visual experience in "blind" regions of the visual field owing to lesions in the visual cortex. As a result, they do not initiate spontaneous reasoning, action or verbal reports directed towards stimuli in the blind field, but they are nevertheless reliable in discriminating stimuli in the blind field under forced choice conditions. For example, when asked to guess whether a presented item is an ' $\mathrm{X}$ ' or an ' $\mathrm{O}$ ', patients are able to report correctly in a high proportion of trials. What explains this reliability is the fact that perceptual information from stimuli in the blind field is represented and processed, although it does not surface in conscious experience..$^{15}$

Does unconscious perceptual information in blindsight provide a source of justification for beliefs about stimuli in the blind field? Intuitively, it does not. After all, blindsighted subjects are not at all disposed to use unconscious perceptual information in forming beliefs about stimuli in the blind field. Instead, they tend to regard their reports in forced choice tasks as mere guesswork and express surprise when informed of their reliability. ${ }^{16}$ Moreover, this seems perfectly reasonable. Blindsight is not plausibly regarded as a cognitive deficit in which subjects are in possession of perceptual evidence that justifies forming beliefs about the blind field, although they are cognitively disabled from using it in forming justified beliefs. On the contrary, it is more plausibly regarded as a perceptual deficit in which subjects 
lack the perceptual evidence that is needed to justify forming beliefs about the blind field in the first place. Intuitively, subjects with blindsight have no more justification to form beliefs on the basis of unconscious perceptual information than to form beliefs on the basis of blind guesswork.

These questions about the epistemic status of blindsight cannot be settled by appealing to facts about its reliability, since the clairvoyance case shows that reliability is not sufficient for epistemic justification. Indeed, blindsighted subjects with blindsight are in much the same epistemic predicament as clairvoyant subjects. They have a reliable perceptual mechanism, which enables them to make accurate guesses on the basis of representation and processing of unconscious perceptual information about stimuli in the blind field. However, they have no justification to believe that they have this reliable mechanism, since the relevant perceptual information is represented and processed unconsciously. Intuitively, then, blindsight is no more a source of justification than clairvoyance.

Of course, subjects with blindsight may eventually learn of their own reliability through induction or testimony and so acquire inferentially mediated justification for beliefs about the blind field. So, for instance, they might be justified in believing that their guesses are likely to be true on the grounds that they've been true in the past. In that case, however, their justification does not have its source in unconscious perceptual information, but solely in background beliefs that are independently justified. In normally sighted subjects, by contrast, justification for beliefs about the external world has its source in phenomenal character of perceptual experience and not solely in independently justified background beliefs. 
The epistemic asymmetry between conscious sight and blindsight seems best explained by the corresponding phenomenal asymmetry between them. This suggests a version of mentalism on which a mental state plays an epistemic role in determining epistemic justification if and only if it is phenomenally conscious:

Phenomenal Mentalism: One's phenomenally conscious mental states determine which doxastic attitudes one has justification to hold.

Nevertheless, there are functional differences, as well as phenomenal differences, between conscious sight and blindsight. We should therefore consider whether the epistemic asymmetry between conscious sight and blindsight can be explained in terms of functional differences, rather than phenomenal differences.

Block (1997) suggests that our ordinary concept of consciousness is a "mongrel concept" that conflates a phenomenal concept with certain functionally defined concepts, including access consciousness and metacognitive consciousness. According to Block's definition, "A state is access conscious if it is poised for direct control of thought and action" (1997: 382). Meanwhile, a metacognitively conscious state is defined as "a state accompanied by a thought to the effect that one is in that state ... arrived at nonobservationally and noninferentially" (1997: 390). Now, conscious sight is conscious in all of these senses, whereas blindsight is conscious in none of these senses. So, why explain the epistemic asymmetry between conscious sight and blindsight in terms of phenomenal consciousness, rather than access consciousness or metacognitive consciousness? 
Block claims, in my view plausibly, that the phenomenal concept of consciousness is distinct from any functionally defined concept and so there are conceptually possible cases in which they come apart. For instance, it is conceptually possible that a functional zombie has states that are conscious in any functionally defined sense, although not in the phenomenal sense. One might reasonably object that there is no intuitive sense in which the states of a functional zombie are conscious as opposed to mere ersatz functional substitutes for consciousness. For current purposes, though, we can set this issue aside. The key question is whether we can explain the epistemic asymmetry between conscious sight and blindsight in terms of functional differences, rather than phenomenal differences. And for these purposes, we can follow Block in assuming that the functional properties of access and metacognition are neither conceptually necessary nor conceptually sufficient for phenomenal consciousness.

One of the most striking functional differences between blindsight and conscious sight is that unconscious perceptual information in blindsight is not access conscious in the sense that it is poised for use in the direct control of action, reasoning, and verbal report. So, perhaps we can explain the epistemic asymmetry between blindsight and conscious sight by appealing to a version of mentalism on which a mental state plays an epistemic role if and only if it is access conscious:

Access Mentalism: One's access conscious mental states determine which doxastic attitudes one has justification to hold. 
This proposal fails, however, since access consciousness is neither necessary nor sufficient for a mental state to play an epistemic role.

A counterexample to necessity is provided by perceptual experience in the absence of attention. ${ }^{17}$ The functional role of attention is, roughly, to make information access conscious in the sense that it is poised for use in the direct control of thought and action. Information that is represented in perceptual experience in the absence of attention is not access conscious and so it cannot play an epistemic role in providing subjects with doxastically justified beliefs. Arguably, however, it can play an epistemic role in providing subjects with propositional justification to form beliefs, even if they cannot use this in forming doxastically justified beliefs in the absence of conscious attention. On this view, there is an important epistemic contrast between blindsight on the one hand and inattentional blindness on the other. ${ }^{18}$

A counterexample to sufficiency is provided by Block's hypothetical case of super-blindsight, which is just like ordinary blindsight except that the subject is disposed to use unconscious perceptual information in the direct and spontaneous control of thought and action without any need for prompting. ${ }^{19}$ That is to say, perceptual information in super-blindsight is access conscious, but not phenomenally conscious. Notwithstanding these functional differences, however, the super-blindsighter is in the same epistemic predicament as the blindsighter. The only relevant difference is that the super-blindsighter is disposed to form beliefs about objects in the blind field automatically and with confidence, whereas the ordinary blindsighter is disposed to make tentative guesses under conditions of 
prompting. However, the mere feeling of confidence is not sufficient to justify forming beliefs - justification is not that easy to come by! In effect, the only relevant difference between blindsight and super-blindsight is the addition of a reliable doxastic disposition, but as the clairvoyance case illustrates, the mere fact that beliefs are formed in a reliable way is not sufficient to make them justified.

Another striking functional difference between blindsight and conscious sight is that unconscious perceptual information in blindsight is not metacognitively conscious in the sense that it is accompanied by higher-order thoughts that are formed in a non-inferential and non-observational way. So, perhaps we can explain the epistemic asymmetry between blindsight and conscious sight by appealing to a version of mentalism on which a mental state plays an epistemic role if and only if it is metacognitively conscious: ${ }^{20}$

Metacognitive Mentalism: One's metacognitively conscious mental states determine which doxastic attitudes one has justification to hold.

Once again, however, this proposal fails, since metacognitive consciousness is neither necessary nor sufficient for a mental state to play an epistemic role.

A counterexample to necessity is provided by the perceptual experiences of unreflective creatures, including young children and higher animals, who can form justified beliefs about the world but cannot form beliefs about their own experience. Evidence from developmental psychology suggests that three-year-old children do not have the conceptual resources required to understand questions about whether 
their beliefs are formed on the basis of perception, inference, or testimony. ${ }^{21}$ However, it would be an over-intellectualization to deny that their beliefs about the world can be justified on the basis of perceptual experience unless they can also form higher-order beliefs about the experiences on which their beliefs are based.

A counterexample to sufficiency is provided by the hypothetical case of hyper-blindsight, which is just like super-blindsight except that the subject has a reliable disposition to form higher-order thoughts about unconscious perceptual information in a non-inferential and non-observational way. That is to say, perceptual information in hyper-blindsight is both access conscious and metacognitively conscious, but not phenomenally conscious. Notwithstanding these functional differences, however, the hyper-blindsighter is in much the same epistemic predicament as the super-blindsighter. The only relevant difference is that the hyper-blindsighter is reliable not only about stimuli in his blind field, but also about the unconscious perceptual representations that carry information about those stimuli. Once again, however, the mere addition of a reliable disposition is not sufficient to make a justificational difference from the original blindsight case. If adding a reliable first-order doxastic disposition is not sufficient to justify firstorder beliefs about the external world, then why should adding a reliable secondorder doxastic disposition be sufficient to justify higher-order beliefs about the internal world? Intuitively, the hyper-blindsighter's higher-order beliefs about his unconscious perceptual states are no more justified than the super-blindsighter's beliefs about objects in the blind field. And we cannot turn unjustified beliefs into justified beliefs by adding more unjustified beliefs! 
The moral to be drawn from the discussion so far is that conscious perceptual experience justifies belief in virtue of its phenomenal character, rather than its functional role. No matter how much we complicate its functional role, unconscious perceptual information cannot play the epistemic role of conscious perceptual experience. A functional zombie has unconscious states that exactly duplicate the causal role of conscious perceptual experiences, but they do not thereby provide justification to form beliefs about the world. Therefore, we cannot explain the epistemic asymmetry between conscious sight and blindsight except in terms of the epistemic role of phenomenal consciousness.

\section{III}

The appeal to phenomenal consciousness as the basis of epistemic justification needs to be handled carefully. In this section, I will argue that phenomenal consciousness is neither necessary nor sufficient for a mental state to play a role in determining epistemic justification and so the following version of phenomenal mentalism is false:

Phenomenal Mentalism I: One's phenomenally conscious mental states determine which doxastic attitudes one has justification to hold.

Nevertheless, I will argue that these counterexamples can be avoided by a version of phenomenal mentalism on which the mental states that play a role in determining 
epistemic justification are phenomenally individuated in a sense to be explained. I therefore propose the following amended version of phenomenal mentalism:

Phenomenal Mentalism II: One's phenomenally individuated mental states determine which doxastic attitudes one has justification to hold.

The first problem is that phenomenal consciousness is not sufficient for a mental state to play a role in determining epistemic justification. As we have already seen, factive mental states, such as seeing that there is a cup on the desk, do not play this kind of epistemic role. For instance, my envatted phenomenal duplicate has as much justification as I do for believing that there is a cup on the desk, although he does not share my factive mental state of seeing that there is a cup on the desk. And yet my factive mental state is phenomenally conscious in the sense that there is something it is like for me to see that there is a cup on the desk. To solve this problem, we need the notion of a phenomenally individuated mental state - that is, a type of mental state that is individuated by its phenomenal character in the sense that all and only tokens of that type have the same phenomenal character. Factive mental states are phenomenally conscious, but they are not phenomenally individuated, since not all mental states with the same phenomenal character are factive mental states. ${ }^{22}$

The second problem is that phenomenal consciousness is not necessary for a mental state to play a role in determining epistemic justification. After all, beliefs play an epistemic role in justifying other beliefs. Indeed, Davidson (1986) went as far as to claim that nothing can justify a belief except another belief. This is surely an 
over-reaction, since beliefs can also be justified by perceptual experiences, which are distinct from the beliefs they justify. And yet it is surely an over-reaction in the opposite direction to claim that beliefs can never be justified by other beliefs. Nevertheless, beliefs are not phenomenally conscious states: they are disposed to cause phenomenally conscious states of judgment, but these dispositions need not be manifested for beliefs to play an epistemic role. To illustrate the point, suppose you observe that the streets are wet and infer that it has been raining. Your justification to draw this conclusion depends on all sorts of background beliefs about the relative probability of various hypotheses conditional on the streets being wet. More generally, which conclusions one has inductive justification to draw from observed evidence depends upon vast amounts of background information that is represented unconsciously in the belief system and not all of this can be brought into consciousness in the process of drawing a conclusion.

This problem can be made more acute by connecting it with Goldman's (1999) "problem of forgotten evidence". Many of our beliefs are formed on the basis of evidence that is subsequently forgotten, although these beliefs themselves are retained. Moreover, it seems that we are often justified in retaining these beliefs despite forgetting the evidence on which they were originally based. The problem is to explain what makes these beliefs justified. For instance, there need be nothing in my current conscious experience that justifies my belief that Henry the Eighth had six wives. Perhaps I am disposed to have an experience in which it seems to me that Henry the Eighth had six wives. ${ }^{23}$ But first, my belief is already justified before this 
disposition is manifested. And second, this disposition cannot justify my belief, since my belief is what explains why I have this disposition in the first place.

A more promising response to the problem of forgotten evidence appeals to the principle of doxastic conservatism, which states that if one already believes that $p$, then one thereby has defeasible justification to retain one's belief that $p .{ }^{24}$ This does not imply the absurd claim that I have defeasible justification to believe that $p$ when I do not already believe that $p$. On the contrary, the principle of doxastic conservatism justifies retaining beliefs that I already have, rather than forming beliefs anew. So, for instance, if I already believe that Henry the Eighth had six wives, then I have defeasible justification to retain my belief regardless of how it was originally formed, although it can be defeated - for instance, by evidence that my belief was originally formed in an unreliable way. In the absence of defeaters, however, I am default justified in retaining my belief despite having forgotten the evidence on which it was originally formed. As a result, which beliefs I have justification to hold at any given time depends in large part on which beliefs I already hold at that time. Phenomenal duplicates that have the same experiences but differ in their background beliefs may thereby differ in which beliefs they have justification to hold.

Any plausible answer to the generalization question must therefore be permissive enough to include beliefs, while also being restrictive enough to exclude subdoxastic mental representations, such as unconscious perceptual information in blindsight. What is needed is an account of what beliefs and experiences have in common in virtue of which they play their epistemic role. However, many are 
pessimistic about the prospects for giving a unified account of the mental that includes beliefs as well as experiences. Thus, Rorty (1979:22) writes, "The attempt to hitch pains and beliefs together seems ad hoc - they don't seem to have anything in common except our refusal to call them 'physical'."

In my view, however, this pessimism can be resisted. The key is to recognize two distinct but related senses in which a mental state can be phenomenally individuated. A type of mental state is phenomenally individuated in the primary sense if and only if it is individuated wholly by phenomenal character - that is, all and only tokens of that type have the same phenomenal character. In contrast, a type of mental state is phenomenally individuated in the derivative sense if and only if it is individuated wholly by phenomenal dispositions - that is, all and only tokens of that type have the same dispositions to cause mental states that are phenomenally individuated in the primary sense.

Beliefs are not phenomenally conscious experiences, but they are disposed to cause phenomenally conscious experiences of judgment. These phenomenally conscious experiences of judgment are individuated wholly by their phenomenal character in the sense that all and only judgments of the same kind have the same phenomenal character. Moreover, beliefs are individuated wholly by their phenomenal dispositions in the sense that all and only beliefs of the same kind have the same phenomenal dispositions. So, phenomenally conscious experiences of judgment and unconscious states of belief are both phenomenally individuated, but in different ways: judgments are individuated by their phenomenal character, whereas beliefs are individuated by their phenomenal dispositions. ${ }^{25}$ 
Subdoxastic mental representations, unlike beliefs, are not individuated wholly by their phenomenal dispositions. On the contrary, they are individuated at least in part by their dispositions to play a role in unconscious computational processes. To illustrate the point, consider Davies' (1989) hypothetical example of states of tacit knowledge of language that are disposed to cause phenomenally conscious itches or tickles. Presumably, what makes it the case that these states embody tacit knowledge of language is not their disposition to cause itches and tickles, but rather their roles in linguistic processing.

A similar point emerges from reflection on Quine's (1970) challenge to Chomsky's (1965) notion of tacit knowledge. The challenge is to explain what constitutes tacit knowledge of a rule if it is less demanding than explicit knowledge of the rule, but more demanding than merely exhibiting linguistic behavior that conforms to the rule. The standard account is that tacit knowledge of a rule is a matter of having the right kind of causal structure in the psychological processing that underpins one's linguistic behavior. More specifically, one has tacit knowledge of a rule if and only if the causal structure of one's psychology mirrors the logical structure of a theory that includes that rule. ${ }^{26}$ There could be two subjects that exhibit the same linguistic behavior, although their behavior is explained by psychological processes that embody tacit knowledge of different linguistic rules. Therefore, tacit knowledge is individuated not merely by its disposition to cause linguistic behavior, but also by its role in unconscious psychological processes.

This point can be generalized to other subdoxastic mental representations, including those involved in vision. There could be two subjects that have the same 
visual experiences, although their visual experiences are explained by different kinds of visual processing involving different representations and rules. Thus, visual representations and rules are individuated not just by their role in explaining conscious experience, but also by their role in psychological processing that occurs beneath the level of phenomenal consciousness.

In this way, we can answer the generalization question in a way that explains why beliefs, unlike subdoxastic mental representations, play an epistemic role in determining epistemic justification because they are individuated wholly by their phenomenal dispositions. This proposal relies on some controversial commitments in the philosophy of mind that I cannot fully defend in this chapter. Instead, I will briefly mention these commitments, explain why I am committed to them, and reference more extended discussions elsewhere. ${ }^{27}$ My own view is that each of these commitments can be defended on its own merits, but in addition, I claim that the arguments of this chapter provide additional theoretical support for these commitments insofar as they are indispensable for making sense of the epistemic role of phenomenal consciousness.

The first commitment is intentionalism: all phenomenal properties are identical with intentional properties. ${ }^{28}$ Intentionalism is needed for responding to the objection that mental states are individuated by their intentional properties, rather than their phenomenal properties. If intentionalism is true, then we need not choose between these ways of individuating mental states, since their phenomenal properties are identical with intentional properties. 
The second commitment is the thesis that intentionalism can be extended from perception to cognition in the following sense: both perceptual and cognitive experiences have intentional properties that are identical with their phenomenal properties. This extended version of intentionalism is needed in order to defend the claim that the phenomenal properties of judgment are specific enough to individuate their intentional contents and attitude-type. In a slogan, the phenomenal properties of judgment are content-specific and attitude-specific. ${ }^{29}$

The third commitment is anti-reductionism: not all phenomenal properties are identical with low-level properties of sensory perception. Anti-reductionism is needed to block the objection that the phenomenal properties of judgment are identical with low-level properties of sensory perception that underdetermine the intentional properties of judgment. This objection can be avoided if the phenomenal properties of judgment are either sui generis, non-sensory properties or high-level sensory properties that correspond to the experience of semantic content. ${ }^{30}$

The fourth commitment is narrow intentionalism: some intentional properties are narrow (i.e. intrinsic) properties of the subject. This is a consequence of intentionalism together with the plausible assumption that all phenomenal properties are narrow properties. ${ }^{31}$ However, narrow intentionalism does not imply that all intentional properties are narrow properties. On the contrary, it is consistent with the plausible claim that some intentional properties are wide, extrinsic properties that depend upon the subject's relations to the external world. ${ }^{32}$ The fifth commitment is a consequence of narrow intentionalism combined with phenomenal mentalism: namely, that mental states play an role in determining 
epistemic justification in virtue of their narrow intentional properties, rather than their wide intentional properties. On this view, which intentional contents one believes depends on one's relations to the external world, but which intentional contents one has justification to believe depends only upon one's narrow, intrinsic properties. Thus, Oscar on Earth and Toscar on Twin Earth have justification to believe all the same intentional contents, although they believe different intentional contents in virtue of their different relations to the external world. ${ }^{33}$

The final commitment is that beliefs are individuated by their phenomenal dispositions, as opposed to their behavioral dispositions. Much of the resistance to this proposal can be undercut by defending the commitments mentioned above. But one might accept that beliefs are disposed to cause judgments that are individuated by their phenomenal character, while denying that beliefs are individuated wholly by these dispositions. So, the question arises, why should we privilege phenomenal dispositions over behavioral dispositions in the individuation of belief?

The main argument of this section is that the phenomenal individuation of belief is indispensable for explaining the epistemic asymmetry between beliefs and subdoxastic mental representations. This argument has an open-ended character, but it raises a challenge for opponents to explain the epistemic asymmetry between beliefs and subdoxastic mental representations in other ways. Moreover, the main argument of the next section is that beliefs and other mental states play an epistemic role only if they are introspectively accessible and they are introspectively accessible only if they are phenomenally individuated. This provides another more theoretical line of argument for the phenomenal individuation of belief. 
My aim so far has been to address the following generalization question:

The Generalization Question: Which mental states play an epistemic role in determining which doxastic attitudes one has justification to hold?

In response to this question, I have argued for a version of phenomenal mentalism on which one's phenomenally individuated mental states determine which doxastic attitudes one has justification to hold. In this section, I want to address a related explanatory question:

The Explanatory Question: Why do some mental states, rather than others, play an epistemic role in determining which doxastic attitudes one has justification to hold?

In response to this question, I will argue that all mental states that determine epistemic justification are introspectively accessible and all introspectively accessible mental states are phenomenally individuated.

It is important to distinguish between ambitious and modest strategies for answering the generalization question. The ambitious strategy seeks to derive the connection between phenomenal consciousness and epistemic justification from more fundamental facts that do not presuppose it. In my view, the ambitious 
strategy cannot succeed, since the connection between phenomenal consciousness and epistemic justification is fundamental and so cannot be derived from anything more fundamental. Instead, I pursue the more modest strategy of arguing that we can acquire some reflective understanding of the connection between phenomenal consciousness and epistemic justification by recognizing how it explains the independently motivated thesis of access internalism.

Access internalism is the thesis that epistemic facts about which doxastic attitudes one has justification to hold are accessible to one by introspection and a priori reflection alone. We can define a fact or a condition $\mathrm{C}$ to be accessible just in case the following conditions obtain:

(1) C obtains if and only if one has justification to believe that $\mathrm{C}$ obtains; and

(2) C fails to obtain if and only if one has justification to believe that $C$ fails to obtain.

Therefore, access internalism is committed to the following principles:

(1) One has justification for some doxastic attitude if and only if one has justification for believing on the basis of introspection and a priori reflection alone that one has justification for that doxastic attitude.

(2) One lacks justification for some doxastic attitude if and only if one has justification for believing on the basis of introspection and a priori reflection alone that one lacks justification for that doxastic attitude. 
Notice that access internalism is formulated here as a thesis about propositional justification, rather than doxastic justification, and so it avoids many standard objections. In particular, there is no commitment to the claim that having justified beliefs requires having (or even having the capacity for) justified beliefs about one's justified beliefs. In other work, I have argued for access internalism and defended it against objections, but for reasons of space, I will not rehearse those arguments here. ${ }^{34}$ Instead, I will argue for the conditional claim that if access internalism can be independently motivated, as I believe it can, then we can use it in explaining the connection between phenomenal consciousness and epistemic justification.

If access internalism is true, then an account of the determinants of epistemic justification must explain why it is true. Reliabilism, for instance, cannot explain why access internalism is true, since the non-epistemic facts about the reliability of one's doxastic dispositions are not accessible by introspection and reflection alone. This point is illustrated clearly enough by the examples of envatment and clairvoyance with which we began: my envatted duplicate has unreliable doxastic dispositions, but he has justification to believe that they are reliable, whereas my clairvoyant duplicate has reliable doxastic dispositions, but he does not have justification to believe that they are reliable.

What explains why epistemic facts about which doxastic attitudes one has justification to hold are accessible on the basis of introspection and a priori reflection alone? As far as I can see, there is only one plausible candidate for such an explanation. First, these epistemic facts must be determined by non-epistemic facts 
about one's mental states that are accessible by introspection. And second, they must be determined in ways that are accessible by a priori reflection. More precisely, for every accessible epistemic fact $\mathrm{E}$, there must be some non-epistemic fact about one's mental states, M, such that it is accessible by introspection that $M$ and it is accessible by a priori reflection that if $\mathrm{M}$, then $\mathrm{E}$. That is to say, access internalism is explained by the introspective accessibility of the mental states that determine epistemic justification together with the a priori accessibility of the way in which it is determined.

Access internalism therefore provides the rationale for a version of introspective mentalism on which the mental states that determine epistemic justification are introspectively accessible in the following sense:

(1) One has mental state $M$ if and only if one has justification to believe on the basis of introspection that one has $\mathrm{M}$; and

(2) One lacks mental state M if and only if one has justification to believe on the basis of introspection that one lacks M.

But this version of introspective mentalism raises two further questions. First, what explains the fact that some mental states are introspectively accessible? And second, if some mental states are introspectively accessible, then which ones?

Let us begin with the first question. Reliabilism cannot explain the fact that some mental states are introspectively accessible. According to reliabilism, one has introspective justification to believe that one has a certain kind of mental state if and 
only if one has an introspective mechanism that disposes one to believe that one has a mental state of that kind. On this view, however, one's mental states are not introspectively accessible in the sense defined unless one's introspective mechanisms are perfectly reliable in the sense that one is disposed to believe that one is in a certain kind of mental state if and only if one is in a mental state of that kind. However, standard forms of reliabilism do not make it a requirement for justification that one's doxastic dispositions are perfectly reliable, but only that they are sufficiently reliable to meet some less perfectly demanding threshold.

In other work, I have argued for a simple theory of introspection on which introspective justification is a primitive and sui generis kind of justification that cannot be assimilated to any more general theory of justification that includes perceptual, inferential, or any other kind of justification. ${ }^{35}$ According to the simple theory, introspective justification is a distinctive kind of justification for believing that one is in a certain kind of mental state, which has its source in the fact that one is in a mental state of that very kind. A consequence of the simple theory is that any mental state that is a source of introspective justification is introspectively accessible in the sense defined above.

Why should we accept the simple theory of introspection? The simple theory is motivated in part by reflection on examples: for instance, if I am in pain, then I have introspective justification to believe that I am in pain just by virtue of the fact that I am in pain; and similarly, if I am thinking about rhubarb, then I have introspective justification to believe that I am thinking about rhubarb just by virtue of the fact that I am thinking about rhubarb. But the strongest theoretical motivation 
for the simple theory of introspection is that it is needed in order to explain the truth of access internalism.

Given that some mental states are introspectively accessible, the question arises, which ones? This is, in effect, another generalization question:

Another Generalization Question: Which mental states are introspectively accessible in the sense that one has introspective justification to believe that one is in mental state $\mathrm{M}$ if and only if one is in $\mathrm{M}$ ?

Assuming introspective mentalism, however, we can use our answer to this question about which mental states are introspectively accessible in constraining our answer to the question of which mental states play an epistemic role in determining epistemic justification.

Not all mental states are introspectively accessible. Here again, we can appeal to the subdoxastic mental representations that figure in computational explanations in cognitive science, such as Chomsky's (1965) tacit knowledge of syntax and Marr's (1982) primal, 2.5D and 3D sketch. After all, our justification to believe that we have these mental states derives from scientific theory, rather than introspection. Thus, we need some restriction on which mental states are introspectively accessible.

An initially promising criterion is that a mental state is introspectively accessible if and only if it is phenomenally conscious. However, this criterion is too restrictive, since it excludes not only subdoxastic mental states, but also beliefs. Beliefs are standing states that persist through time without making any ongoing 
contribution to phenomenal consciousness. For instance, my belief that Canberra is the capital of Australia persists whether or not I am consciously considering the matter and so does my second-order belief that I believe this. As we have already seen, there is a problem in explaining the source of my justification for these beliefs, since there may be nothing in my stream of phenomenal consciousness that makes them justified at any given time. Moreover, in many cases, it is not plausible that my beliefs are inferentially justified by their relations to other beliefs, since I may be unable to remember anything that is relevant to their justification. In the case of second-order beliefs, though, it is plausible to suppose that they are justified by the presence of the corresponding first-order beliefs, regardless of whether and if so, how those first-order beliefs are justified. So, just as I have introspective justification to believe that I am in pain just by virtue of being in pain, so I have introspective justification to believe that I believe that Canberra is the capital of Australia just by virtue of the fact that I believe it. ${ }^{36}$

As before, we need an answer to the generalization question that is permissive enough to include beliefs, but also restrictive enough to exclude subdoxastic states. What we need, then, is a criterion that explains what beliefs, unlike subdoxastic states, have in common with phenomenally conscious states in virtue of which they are introspectively accessible. One strategy is to answer the generalization question by appealing to some broadly functionalist criterion on which a mental state is introspectively accessible if and only if plays a certain functional role. The challenge for proponents of this strategy is to identify some 
functional property that beliefs have in common with phenomenally conscious experiences, but not with subdoxastic states.

For instance, one might propose that a mental state is introspectively accessible if and only if it is access conscious in the sense that it is poised for use in the direct control of thought and action. ${ }^{37}$ After all, beliefs are typically access conscious, whereas subdoxastic mental representations are typically not. Nevertheless, we can generate counterexamples by imagining subdoxastic mental representations that are access conscious, but not phenomenally conscious, such as Block's example of super-blindsight in which unconscious perceptual information is poised for use in the direct control of thought and action. Intuitively, the superblindsighter does not have introspective justification to form beliefs about what is represented in her visual system any more than the regular blindsighter does. At best, she has justification to make inferences about what is represented in her visual system from observational data about her own spontaneous verbal and non-verbal behavior. Therefore, access consciousness is not sufficient for introspective accessibility.

One might respond by imposing a more demanding functional criterion on which a mental state is introspectively accessible if and only if it is metacognitively conscious in the sense that it is accompanied by a higher-order thought that is arrived at in the right way. Once again, we can generate counterexamples by imagining subdoxastic mental representations that are metacognitively conscious, but not phenomenally conscious, such as the case of hyper-blindsight in which unconscious perceptual representations are reliably disposed to cause higher-order 
thoughts of the right kind. Intuitively, the hyper-blindsighter has no more introspective justification to form beliefs about her unconscious perceptual representations than the super-blindsighter does. Certainly, she has a reliable disposition to form true beliefs about her unconscious visual representations, but this is not sufficient to make her beliefs introspectively justified. By analogy, the super-blindsighter has a reliable disposition to form true beliefs about stimuli in the blind field, but this is not sufficient to make them perceptually justified. So why should we suppose that the hyper-blindsighter's beliefs about her unconscious visual representations are any more justified than the super-blindsighter's beliefs about objects in the blind field? Therefore, metacognitive consciousness is not sufficient for introspective accessibility.

In response to the generalization question, I propose a phenomenal introspection thesis, which states that one's mental states are introspectively accessible if and only if they are phenomenally individuated. On this proposal, phenomenal experiences and beliefs, unlike subdoxastic states, are introspectively accessible in virtue of being individuated by their relations to phenomenal consciousness. Phenomenal experiences of judgment are introspectively accessible because they are individuated by their phenomenal character, whereas beliefs are introspectively accessible because they are individuated by their dispositions to cause phenomenal experiences of judgment that are also introspectively accessible. This is not to say that one's introspective justification for second-order beliefs about one's beliefs has its source in phenomenally conscious judgments. ${ }^{38}$ On the contrary, one's introspective justification for second-order beliefs about one's beliefs has its 
source in one's first-order beliefs themselves. These first-order beliefs are individuated by their dispositions to cause phenomenally conscious judgments, but these dispositions need not be manifested in order for having introspective justification for second-order beliefs or for using it in holding introspectively justified second-order beliefs.

In summary, the following three claims form a coherent and mutually reinforcing package in which any two of these claims entails the third:

(1) Introspective Mentalism: One's introspectively accessible mental states determine which doxastic attitudes one has justification to hold.

(2) The Phenomenal Introspection Thesis: One's introspectively accessible mental states are just one's phenomenally individuated mental states.

(3) Phenomenal Mentalism: One's phenomenally individuated mental states determine which doxastic attitudes one has justification to hold.

Therefore, we can argue for phenomenal mentalism by appealing to the epistemic role of phenomenal consciousness in introspection together with introspective mentalism, which is a consequence of access internalism. Can we further explain the connection between introspection and phenomenal consciousness? I suspect that we cannot except by appealing to a more general connection between phenomenal consciousness and epistemic justification. That is why the explanatory strategy that I am offering is modest rather than ambitious. We can argue for a more general connection between phenomenal consciousness and epistemic justification by 
appealing to a more specific connection between phenomenal consciousness and its epistemic role in introspection, but we cannot motivate the connection in a way that does not presuppose it at all.

Moreover, we can acquire some reflective understanding of the connection between epistemic justification and phenomenal consciousness by recognizing how it explains the truth of access internalism. And we can use this reflective understanding to explain and justify the intuitive judgments about cases that we began with. Given access internalism, we can infer the conclusion that my envatted duplicate has justification to form beliefs on the basis of perceptual experience from the premise that he has justification to believe on the basis of introspection and a priori reflection alone that he has justification to form beliefs in this way. Similarly, we can infer the conclusion that my clairvoyant duplicate lacks justification to form beliefs on the basis of blind hunches or wishful thinking from the premise that he lacks justification to believe that he has justification to form beliefs in this way. And likewise for blindsighters, super-blindsighters, and hyper-blindsighters.

These judgments are not simply brute deliverances of intuition, but can be regarded as consequences of an independently motivated theory of justification. In this way, intuition and theory can be brought into reflective equilibrium. ${ }^{39}$ 


\section{References}

Armstrong, David. 1968. A Materialist Theory of the Mind. London: Routledge.

Audi, Robert. 2001. "An Internalist Theory of Normative Grounds." Philosophical

Topics 23: 31-45.

Ayers, Michael. 1991. Locke: Epistemology and Ontology. New York: Routledge.

Bergmann, Michael. 2006. Justification Without Awareness: A Defense of Epistemic Externalism. New York: Oxford University Press.

Block, Ned. 1997. "On a Confusion About a Function of Consciousness." In The Nature of Consciousness: Philosophical Debates, edited by N. Block, O. Flanagan and G. Guzeldere. Cambridge: MIT Press.

BonJour, Laurence. 1980. "Externalist Theories of Empirical Knowledge." Midwest Studies in Philosophy 5 (1): 53-74.

Brewer, Bill. 1999. Perception and Reason. Oxford: Oxford University Press.

Chalmers, David. 1995. "Facing Up to the Problem of Consciousness." Journal of Consciousness Studies 2 (3): 200-219.

Chalmers, David. 2004. "The Representational Character of Experience." In The Future for Philosophy, edited by B. Leiter. New York: Oxford University Press.

Chomsky, Noam. 1965. Aspects of the Theory of Syntax. Cambridge: MIT Press.

Christensen, David. 1994. "Conservatism in Epistemology." Nous 28 (1): 69-89.

Cohen, Stewart. 1984. "Justification and Truth." Philosophical Studies 46: 279-295.

Conee, Earl and Feldman, Richard. 2001. "Internalism Defended." American Philosophical Quarterly 38 (1): 1-18.

Davidson, Donald. 1986. "A Coherence Theory of Truth and Knowledge." In Truth and Interpretation: Perspectives on the Philosophy of Donald Davidson, edited by E. LePore. Oxford: Blackwell, 1986.

Davies, Martin. 1987. "Tacit Knowledge and Semantic Theory: Does a Five Percent Difference Matter?" Mind 96: 441-62.

Davies, Martin. 1989. "Tacit Knowledge and Subdoxastic States." In Reflections on Chomsky, edited by A. George. Oxford: Blackwell.

Dennett, Daniel. 1969. Content and Consciousness. New York: Routledge.

Dretske, Fred. 1981. Knowledge and the Flow of Information. Stanford: CSLI.

Dretske, Fred. 1995. Naturalizing the Mind. Cambridge: MIT Press.

Evans, Gareth. 1981. "Semantic Structure and Tacit Knowledge.” In Wittgenstein: To Follow a Rule, edited by S. Holtzmann and C. Leich. London: Routledge and Kegan Paul.

Farkas, Katalin. 2008. "Phenomenal Intentionality Without Compromise." Monist 91 (2): 273-93.

Feldman, Richard. 1985. "Reliability and Justification.” Monist 68: 159-174.

Firth, Roderick. 1978. "Are Epistemic Concepts Reducible to Ethical Concepts?" In Values and Morals, edited by A. Goldman and J. Kim. Dordrecht: Kluwer.

Fodor, Jerry. 1987. Psychosemantics. Cambridge: MIT Press.

Foley, Richard. 1985. "What's Wrong with Reliabilism?" Monist 68: 188-202.

Goldman, Alvin. 1979. "What is Justified Belief?” In Justification and Knowledge, edited by G. Pappas. Dordrecht: Reidel.

Goldman, Alvin. 1999. “Internalism Exposed.” The Journal of Philosophy 96: 271-93. 
Gopnik, Alison and Graf, Peter. 1988. "Knowing How You Know: Children's Understanding of the Sources of their Knowledge." Child Development 59: 136671.

Harman, Gilbert. 1986. Change in View: Principles of Reasoning. Cambridge: MIT Press.

Horgan, Terry and Tienson, John. 2002. "The Intentionality of Phenomenology and the Phenomenology of Intentionality." In Philosophy of Mind: Classical and Contemporary Readings, edited by D. Chalmers. New York: Oxford University Press.

Huemer, Michael. 2001. Skepticism and the Veil of Perception. Lanham: Rowman and Littlefield.

Koksvik, Ole. 2011. Intuition. Ph.D. Dissertation, Australian National University. Lehrer, Keith. 1990. Theory of Knowledge. Boulder: Westview.

Lycan, William. 1996. Consciousness and Experience. Cambridge: MIT Press.

Marr, David. 1982. Vision: A Computational Investigation into the Human Representation and Processing of Visual Information. New York: Freeman.

McDowell, John. 1994. Mind and World. Cambridge: Harvard University Press.

McGrath, Matthew. 2005. "Memory and Epistemic Conservatism." Synthese 157: 124.

Millikan, Ruth. 1984. Language, Thought, and Other Biological Categories: New Foundations for Realism. Cambridge: MIT Press.

Nozick, Robert. 1981. Philosophical Explanations. Cambridge: Harvard University Press.

Peacocke, Christopher. 1998. "Conscious Attitudes, Attention, and Self-Knowledge." In Knowing Our Own Minds, edited by C. Wright, B. Smith, and C. MacDonald. New York: Oxford University Press.

Pitt, David. 2004. "The Phenomenology of Cognition, Or, What is it Like to Think that P?" Philosophy and Phenomenological Research 69: 1-36.

Plantinga, Alvin. 1993. Warrant: The Current Debate. Oxford: Oxford University Press.

Prinz, Jesse. 2012. The Conscious Brain: How Attention Engenders Experience. New York: Oxford University Press.

Pryor, James. 2000. "The Skeptic and the Dogmatist." Nous 34: 517-549.

Quine, Willard Van Orman. 1960. Word and Object. Cambridge: MIT Press.

Rorty, Richard. 1979. Philosophy and the Mirror of Nature. Princeton: Princeton University Press.

Ryle, Gilbert. 1949. The Concept of Mind. Chicago: Chicago University Press.

Sellars, Wilfred. 1956. Empiricism and the Philosophy of Mind. Cambridge: Harvard University Press.

Silins, Nicholas. 2012. "Judgment as a Guide to Belief." In Introspection and Consciousness, edited by D. Smithies and D. Stoljar. New York: Oxford University Press.

Silins, Nicholas and Siegel, Susanna. Forthcoming. "Consciousness, Attention, and Justification." In Contemporary Perspectives on Skepticism and Perceptual Justification, edited by E. Zardini and D. Dodd. Oxford: Oxford University Press. 
Shoemaker, Sydney. 2009. "Self-Intimation and Second-Order Belief." Erkenntnis 71: 35-51.

Siewert, Charles. 1998. The Significance of Consciousness. Princeton: Princeton University Press.

Smithies, Declan. 2006. Rationality and the Subject's Point of View. Ph.D. thesis, New York University.

Smithies, Declan. 2011a. "What is the Role of Consciousness in Demonstrative Thought?" The Journal of Philosophy 108 (1): 5-34.

Smithies, Declan. 2011b. "Attention is Rational-Access Consciousness." In Attention: Philosophical and Psychological Essays, edited by C. Mole, D. Smithies and W. Wu. Oxford University Press.

Smithies, Declan. 2012a. "The Mental Lives of Zombies." Philosophical Perspectives 26: 343-72.

Smithies, Declan. 2012b. "Moore's Paradox and the Accessibility of Justification." Philosophy and Phenomenological Research 85 (2): 273-300.

Smithies, Declan. 2012c. "A Simple Theory of Introspection." In Introspection and Consciousness, edited by D. Smithies and D. Stoljar. New York: Oxford University Press.

Smithies, Declan. Forthcoming a. "The Nature of Cognitive Phenomenology." Philosophy Compass.

Smithies, Declan. Forthcoming b. "Why Justification Matters." In Epistemic Evaluation: Point and Purpose in Epistemology, edited by D. Henderson and J. Greco. New York: Oxford University Press.

Strawson, Galen. 1994. Mental Reality. Cambridge: MIT Press.

Sosa, Ernest. 2003. "Beyond Internal Foundations to External Virtues." In Epistemic Justification: Internalism vs. Externalism, Foundations vs. Virtues, edited by L. BonJour and E. Sosa. Oxford: Blackwell.

Stich, Stephen. 1978. "Beliefs and Subdoxastic States." Philosophy of Science 45: 499518.

Tye, Michael. 1995. Ten Problems of Consciousness. Cambridge: MIT Press.

Wedgwood, Ralph. 2002. "Internalism Explained." Philosophy and Phenomenological Research 65: 349-369.

Weiskrantz, Lawrence. 1997. Consciousness Lost and Found: A Neuropsychological Exploration. New York: Oxford University Press.

Weiskrantz, L., Warrington, E., Sanders, M., Marshall, J. 1974. "Visual Capacity in the Hemianopic Field Following a Restricted Occipital Ablation." Brain 97: 709-28.

Williamson, Timothy. 2000. Knowledge and Its Limits. New York: Oxford University Press.

Williamson, Timothy. 2005. "On Being Justified In One's Head." In Rationality and the Good: Critical Essays on the Ethics and Epistemology of Robert Audi, edited by M. Timmons, J. Greco, and A. Mele. New York: Oxford University Press.

Wright, Crispin. 2004. "Warrant for Nothing (and Foundations for Free)?" Aristotelian Society Supplementary Volume 78 (1): 167-212.

Zimmerman, Aaron. 2006. “Basic Self-Knowledge: Answering Peacocke's Criticisms of Constitutivism." Philosophical Studies 128: 337-379. 
1 The distinction between hard and easy problems was introduced by Chalmers (1995), but the program of understanding the mind and our knowledge of the external world without reference to phenomenal consciousness goes back at least as far as Ryle (1949) and is a common thread in the philosophy of Sellars (1956), Quine (1960), Rorty (1979), Putnam (1981), and Davidson (1986).

2 This is perhaps most clearly evident in the attempts to "naturalize" intentionality in the work of Dretske (1981), Fodor (1987), and Millikan (1984).

3 This is a defining feature of the "reliabilist" tradition in epistemology that includes the work of Armstrong (1968), Goldman (1979), Dretske (1981), and Nozick (1981).

4 This is one consequence of "representationalism" or "intentionalism" in philosophy of mind. Reductive representationalists, including Tye (1995), Dretske (1995), and Lycan (1996), claim that the problem of explaining phenomenal consciousness is made easier by its connections with mental representation, while non-reductive representationalists, including Horgan and Tienson (2002) and Chalmers (2004), claim that the problem of explaining mental representation is made harder by its connections with phenomenal consciousness.

${ }^{5}$ Other epistemologists emphasize the role of perceptual experience in explaining our knowledge of the external world, including McDowell (1994), Brewer (1999), and Pryor (2000). My aim in this chapter is to sketch a more general account of the epistemic role of phenomenal consciousness. ${ }^{6}$ See Smithies (2012a) for further discussion of this distinction between strong and weak versions of the thesis that phenomenal consciousness grounds mental representation.

${ }^{7}$ See Firth (1978) for the distinction between "propositional" and "doxastic" justification and Goldman (1979) for a related distinction between "ex ante" and "ex post" justification.

8 Reliabilist theories of justification are proposed by Goldman (1979), Sosa (2003), and Bergmann (2006), although the details of their views raise various complications that I cannot address here.

9 This is a variation on the 'new evil demon problem' originally proposed by Cohen (1984), Feldman (1985) and Foley (1985).

10 The clairvoyance cases were originally proposed by BonJour (1980). Compare Lehrer's (1990) Truetemp case and Plantinga's (1993) case of the epistemically serendipitous lesion.

${ }^{11}$ Proponents of mentalism include Conee and Feldman (2001) and Wedgwood (2002), although they formulate mentalism in terms of supervenience, rather than determination. I focus on "current time-slice" versions of mentalism, rather than "historical" versions, although I leave the temporal operators implicit: thus, one's mental states at a time determine which doxastic attitudes one has justification to hold at that time.

12 Williamson (2000) argues for a factive version of mentalism on which one's evidence, and so which doxastic attitudes one has justification to hold, is determined by one's knowledge, which he claims to be the most general kind of factive mental state.

${ }^{13}$ Stich defines subdoxastic states as "psychological states that play a role in the proximate causal history of beliefs, though they are not beliefs themselves" (1978: 499), but we can add the further stipulation that no subdoxastic states are phenomenally conscious states.

14 Pryor (2000) argues that perceptual experience provides immediate, non-inferential justification for beliefs about the external world, while Wright (2004) argues for the opposing view that it only provides inferentially mediated justification for beliefs about the external world.

${ }^{15}$ See Weiskrantz (1997) for an overview of empirical work on blindsight.

${ }^{16}$ Compare Weiskrantz et al: "When he was shown his results he [patient DB] expressed great surprise and insisted several times that he thought he was just 'guessing"' (1974: 721).

17 Prinz (2012) argues that there cannot be consciousness without attention, but he also denies that attention is sufficient for access consciousness. So, Prinz allows for conscious experience that is not access conscious in Block's sense, which is sufficient to run a version of the counterexample.

${ }^{18}$ See Smithies (2011a) and (2011b) for a more detailed discussion of this proposal. See also Siegel and Silins (forthcoming) who defend a view that is similar to mine.

${ }^{19}$ According to Block, the super-blindsighter is "trained to prompt himself at will, guessing without being told to guess" (1997: 385), but let us suppose instead that he forms beliefs spontaneously without any need for self-prompting. So understood, there are no actual cases of super-blindsight, although there are some cases that fit Block's definition; see Smithies (2011b) for further discussion. 
${ }^{20}$ Ayers (1991) explains the epistemic asymmetry between conscious sight and blindsight in terms of a distinction between primary and secondary knowledge: that is, a distinction between knowing how one knows and knowing without knowing how one knows.

${ }^{21}$ See Gopnik and Graf (1988) for an overview.

22 Object-involving mental states can be treated in much the same way as factive mental states, but object-involving mental states raise special problems that I will briefly touch on below in connection with .

${ }^{23}$ Huemer (2001) appeals to "memory-related seemings" and Conee and Feldman (2001: 9) appeal to "conscious qualities of the recollection, such as its vivacity and...associated feeling of confidence."

24 This view is also sometimes known as 'epistemic conservatism'. See Harman (1986) for a classic discussion and McGrath (2005) for a more recent discussion. See Christensen (1994) for criticisms of conservatism and a coherentist alternative that is also consistent with the proposed version of phenomenal mentalism.

${ }^{25}$ See Smithies (2012a) for a more detailed discussion and defence of this account of the individuation of belief.

${ }^{26}$ See Evans (1981) and Davies (1987) for this account of tacit knowledge.

${ }^{27}$ See Smithies (forthcoming a) for an overview.

${ }^{28}$ Proponents of Intentionalism include Dretske (1995), Tye (1995), Lycan (1995), Siewert (1998), Horgan and Tienson (2002), and Chalmers (2004).

29 The terminology of 'content-specific' and 'attitude-specific' phenomenal properties is borrowed from Ole Koksvik (2011); see also Horgan and Tienson (2002) for a related distinction between the phenomenology of intentional content and the phenomenology of attitude-type.

30 See Strawson (1994), Siewert (1998), Horgan and Tienson (2002), and Pitt (2004) for discussion.

${ }^{31}$ See Pautz (this volume) for discussion. I should note that while I find this assumption plausible, I am not independently committed to it, so my commitment to narrow intentionalism is conditional on the truth of this assumption.

32 See Horgan and Tienson (2002) and Chalmers (2004) for versions of narrow intentionalism on which some intentional properties are wide and Farkas (2008) for a more uncompromising view on which all intentional properties are narrow.

33 Compare Audi (2001) for a related proposal and Williamson (2005) for critical discussion. I plan to defend this proposal against various objections in a more extended discussion elsewhere.

${ }^{34}$ Smithies (2012b) argues that access internalism is needed for explaining the irrationality of certain kinds of epistemic akrasia that are manifested by believing Moorean conjunctions, while Smithies (forthcoming b) argues that access internalism is a consequence of the role of justification as an evaluative ideal for the practice of critical reflection.

${ }^{35}$ See Smithies (2012c).

${ }^{36}$ Compare Zimmerman (2006: 357-61) and Shoemaker (2009: 49-50). See also Peacocke's (1998) NICS cases, in which standing first-order beliefs justify occurrent second-order judgements in the absence of any intermediate conscious state.

${ }^{37}$ For this proposal, see Zimmerman (2006: 357) and Shoemaker (2009). Shoemaker appeals to a concept of availability that is closely related to Block's notion of access consciousness.

${ }^{38}$ Compare Silins (2012) for a contrasting proposal of this view.

39 This chapter reworks some of the central ideas in my Ph.D. dissertation and draws on themes that I have developed in a series of papers and which I plan to bring together in a monograph for Oxford University Press. I have presented these ideas at several venues over the past few years, including ANU, Dubrovnik, Harvard, Melbourne, Ohio State, Fribourg, Northwestern, MIT, and the Pacific APA, as well as the Online Philosophy Conference for New Waves in Philosophy of Mind. I am grateful for feedback on all of those occasions and especially to John Campbell, David Chalmers, Elijah Chudnoff, Terry Horgan, Geoff Lee, Susanna Siegel, Charles Siewert, Nico Silins, and Daniel Stoljar. 